\title{
Instrumented Indentation of Lung Reveals Significant Short Term Alteration in Mechanical Behavior with $100 \%$ Oxygen
}

\author{
Maricris R. Silva, Hsuan-Tso Shen, Ali Marzban and Andrew Gouldstone* \\ Department of Mechanical and Industrial Engineering, Northeastern University
}

\begin{abstract}
In critical care, trauma, or other situations involving reduced lung function, oxygen is given to avoid hypoxia. It is known that under certain conditions and long time (several hours) exposure, oxygen is toxic to the lungs, the possible mechanisms being direct cellular damage or surfactant dysfunction. Our key objective was to investigate possible changes in lung function when exposed to $100 \%$ oxygen in the short term (several tidal volumes). We performed mechanical tests on lobar surfaces of excised mammalian lungs inflated with air or $100 \%$ oxygen, examining (i) stiffness, (ii) non-linear mechanical response and (iii) induced alveolar deformation. Our results showed that within five tidal volumes of breathing $100 \%$ oxygen, lung mechanics are significantly altered. In addition, after five tidal volumes of laboratory air, lung mechanical behavior begins to return to pre-oxygen levels, indicating some reversibility. These significant and short-term mechanical effects of oxygen could be linked to oxygen toxicity.
\end{abstract}

Keywords: lung mechanics, indentation, optical coherence tomography, oxygen toxicity

\section{INTRODUCTION}

Of all the internal organs, the lung has arguably the strongest connection between physiologic function and mechanical behavior. For normal breathing, it requires sufficient compliance and recoil for effective inflation and deflation, respectively. Serious pathologies are associated with sub-optimum mechanical behavior of the lung. These include acute respiratory distress syndrome (ARDS), chronic obstructive pulmonary disease (COPD) and extreme cases of asthma. Some conditions require mechanical ventilation of patients, due to extensive decreased lung function [1-3] , but this in itself can lead to ventilator-induced lung injury (VILI) if alveoli are inflated too aggressively. Accordingly, lung mechanical behavior and its association with physiology have received large attention in the medical and engineering literature. Numerous studies have measured the overall mechanical properties during inflation and deflation via pressure-volume $(P-V)$ relations [4]. Elastic properties of the lung in shear for mechanical modeling have been measured using indentation of excised lobes $[5,6]$.

*Corresponding Author: 267 Snell Engineering, Northeastern University, 360 Huntington Ave, Boston, MA 02115-5000,USA; agouldstone@coe.neu.edu 
In a previous study, Silva et al. performed indentation tests on excised lungs to induce and observe compressive atelectasis (alveolar collapse) under different physiologic conditions [7]. In these tests, lobes of inflated lung were indented under force control with a spherical tip, geometrically similar to that of the rib in the animal model studied. Upon unloading, a 'dent' remained in the surface and persisted until a sufficiently high inflation pressure was applied at the trachea for its recovery. Combined with finite element analysis (FEA) and optical coherence tomography (OCT) to observe collapsed alveoli, it was concluded that such a test served as a sensitive mechanical assay to study lung mechanical behavior at high strains [7], and can complement information from lung function tests

An early discovery in lung physiology remains one of the most profound, that pulmonary surfactant, which lines the alveolar walls, plays an important role in lung function, and defends against or rescue from disease [8-10]. Thus, a key to understanding lung physiology and pathology as well as enabling therapy lies with this phospholipid monolayer. Significant progress has been made in surfactant structural characterization, function, synthesis and role in therapy [11-14]. The above-described indentation test allows indirect investigation of surfactant behavior by combining locally extracted high-strain mechanical properties with sub-surface observations of alveolar distortion, and perhaps controlled collapse under different inflation pressures.

\section{MATERIALS AND METHODS}

\subsection{Lung Test Specimens}

Goat, sheep and bovine calf lungs were obtained from Research 87, Inc. (Boylston, MA). The animals had been handled and sacrificed so that respiratory structures were not affected. Lungs were kept in a refrigerated $\left(\sim 5^{\circ} \mathrm{C}\right)$ container and delivered to the laboratory 1-2 hours after sacrifice. Prior to experiments, lungs were kept in plastic bags and temperature was raised to body temperature $\left(\sim 37^{\circ} \mathrm{C}\right)$ using a water bath. Prior to all experiments, lungs were inflated with air to $25 \mathrm{cmH}_{2} \mathrm{O}$ for a set of 5 cycles (Positive end-expiratory pressure $(\mathrm{PEEP})=0,6$ breaths $/ \mathrm{min}$ rate, $80 \%$ inspiration per cycle). The total experimental time was approximately 60-90 minutes during which the lungs were laid on a flat surface and kept moistened using saline spray. Gas was bubbled through water, but humidity was not recorded.

\subsection{Instrumented Indentation}

In an indentation test, a rigid tip of known geometry (e.g., spherical tip of radius $R$ ) is pressed into a surface with a controlled displacement or depth $h$, with $h=0$ corresponding to initial contact (Fig. 1). Force $P$ is continuously recorded as the tip is driven to $h_{\max }$ and then unloaded; this generates force-displacement $(P-h)$ loading and unloading data that can be analyzed to study material behavior. In our experiments, we used a tip of $R \approx 5.0 \mathrm{~mm}$ attached to a force transducer (Grass FTO3, Grass-Telefactor, West Warwick, RI) driven by a linear actuator (Zaber Technologies, Vancouver) oriented vertically on a rigid shaft. Using this method, the $P$ - $h$ loading and unloading data provide measurements of (i) stiffness in response to a shear distortion, and (ii) dependence of stiffness (nonlinearity) on shear strain, at a particular inflation pressure. 


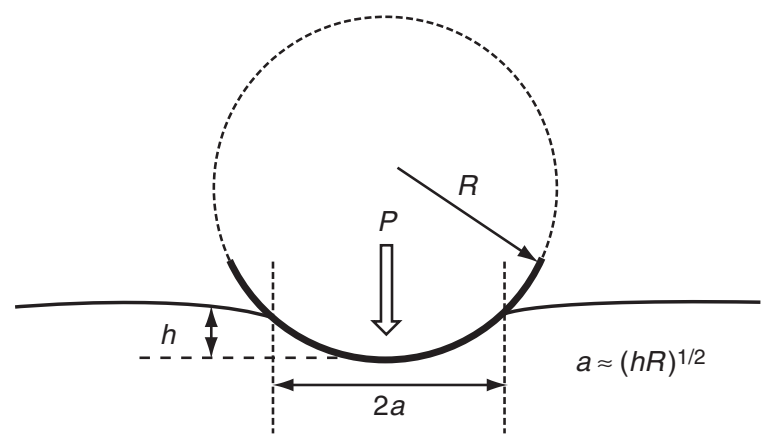

Figure 1. Schematic of spherical indentation with a tip of radius $R$.

\subsection{Optical Coherence Tomography (OCT)}

OCT is an interferometric optical signal acquisition and processing method [15] that has been shown to image alveoli [16-19]. A functional domain OCT system was used with a central wavelength of $930 \mathrm{~nm}$ and a spectral width of $100 \mathrm{~nm}$ that allows a maximum imaging depth of $1.6 \mathrm{~mm}$ with an axial resolution of $6.2 \mu \mathrm{m}$ (OCP930SR, Thorlabs, Inc., Newton, NJ, USA). The system features a handheld probe housing the Michelson interferometer that divides light from a superluminescent diode light source into the reference and sample arms. To allow in situ observation of subsurface deformation of the lungs, a transparent semi-spherical tip of $5.0-\mathrm{mm}$ radius was attached to the probe (Fig. 2). The probe was mounted to a linear actuator that controls the indentation speed and depth.

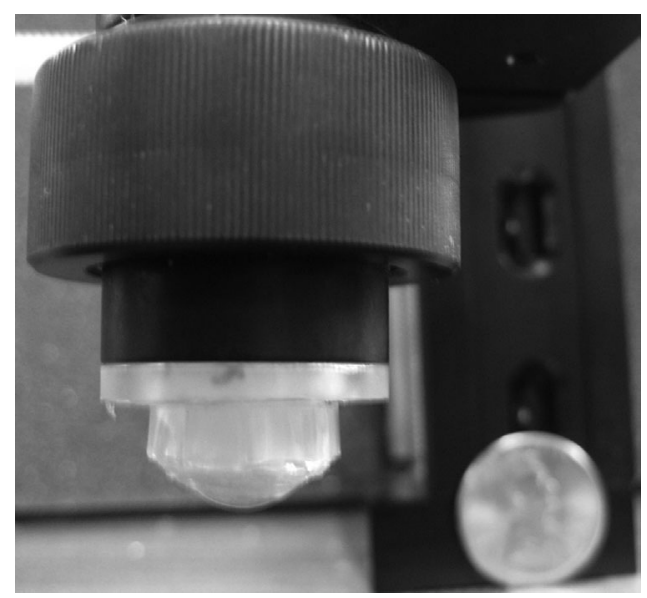

Figure 2. IR-transparent indenter tip used for OCT experiments. 


\subsection{Indentation Experiments}

In an indentation experiment, the lung test specimen was initially held at $25 \mathrm{cmH}_{2} \mathrm{O}$ and indented to 1,2 and $3 \mathrm{~mm}$ depths at a speed of $0.057 \mathrm{~mm} / \mathrm{s}$. This speed was chosen to allow observation of the deformation during both loading and unloading based on the OCT system's capability in terms of the number of image frames that can be saved. Images of subsurface deformation were recorded during the indentation, with the first frame being the image right before loading and the last frame the image at the end of unloading. This protocol was repeated at inflation pressures of 12 and $4 \mathrm{cmH}_{2} \mathrm{O}$, respectively, after which the lung was inflated with $100 \%$ oxygen and the experiment repeated for the same set of inflation cycles prior to indentation at 25, 12 and $4 \mathrm{cmH}_{2} \mathrm{O}$. These pressures were chosen to simulate various levels of deep and quiet breathing. To test the reversibility of the effects of $\mathrm{O}_{2}$, the experiment was repeated with subsequent inflation with air. A total of $\mathrm{n}=16,11$ and 9 data sets from lungs inflated with air, $\mathrm{O}_{2}$, and air again, respectively, were generated. To test the time-dependence of deformation, the same set of experiments was repeated with an indentation speed of $0.0285 \mathrm{~mm} / \mathrm{s}$.

To obtain $P$ - $h$ data, lung specimens were treated following the same procedure with respect to inflation pressure, gas (air or $\mathrm{O}_{2}$ ) and maximum indentation depth. Indentation speeds were $0.003,0.01$ and $0.03 \mathrm{~mm} / \mathrm{sec}$, but as described in Results, very little dependence on this parameter was observed. In the experiments, a particular region was not re-indented so that only one $P$ - $h$ curve was generated for one location in order to reduce the possibility of misinterpreting any indentation damage. This was achieved by moving the tip at least $3 \mathrm{~cm}$ laterally to perform the next indent. Hysteresis for each experiment was calculated by curve-fitting the loading and unloading segments of the $P$ - $h$ curves with MATLAB. The equations obtained were then integrated from 0 to $h_{\max }$ and the difference calculated as the hysteresis value. As the set of experiments were comparative, we report hysteresis ratios between tests with different parameters.

\subsection{Image Analysis}

To quantify deformation from the OCT images, a MATLAB code was written that calculates the progression of deformation. From a set of binary images (tissue $=1$ and gas $=0$ ) that were arranged in sequence of the deformation, the algorithm was designed to take the sum of all the pixel values from a chosen area and compare the changes within this area relative to the first image of the set. Threshold was set to the normalized mean of the pixel values, and closure was defined according to the equation below where, for the chosen area, $\Sigma A_{o}$ is the sum of the pixel values from the first frame and $\Sigma \mathrm{A}_{\mathrm{n}}$ is the sum of the pixel values from the $n$th frame:

$$
\text { Closure }=\frac{\Sigma \mathrm{A}_{\mathrm{n}}-\Sigma \mathrm{A}_{\mathrm{o}}}{\Sigma \mathrm{A}_{\mathrm{o}}} * 100 \%
$$

A modified version of this code was used to quantify the progression of closure along the axis of indentation. In this version, several areas of the same size along the axis of indentation were programmed to quantify changes during the deformation. 


\subsection{Analysis and FEA Modeling}

The purpose of the modeling was to connect sub-surface observations of deformation with $P$ - $h$ data. Considering the spherical indentation of a surface, for a linear elastic material, all relevant equations are analytically tractable, and were initially described by Hertz [20]. The relation between $P$ and $h$ for such a material is given by:

$$
P=\frac{4}{3} E^{*} R^{1 / 2} h^{3 / 2}
$$

where $E^{*}=E /\left(1-v^{2}\right), E$ is Young's modulus and $v$ is Poisson's ratio, typically assumed to be 0.43 for lung [6]. A $P$ - $h$ response with an $h$ exponent different than $3 / 2$ indicates nonlinear material behavior. Conveniently, non-linear material behavior can be approximated by input of a strain $(\varepsilon)$-dependent $E_{\varepsilon}$. In turn, characteristic strain under the indenter is given by $\varepsilon=B(a / R)$, where $a$ is contact radius and $B$ is a constant, or given that $a=(h R)^{1 / 2}, \varepsilon=B(h / R)^{1 / 2}$. Treating the lung as a continuum material, we chose the simplest non-linear model, $E_{\varepsilon}=E_{o} \varepsilon^{n}=E_{o}(B h / R)^{n / 2}$ (Fig. 3). Using this model, we can adapt the above $P$ - $h$ relation to the following:

$$
P=\frac{4}{3} \frac{E_{o}}{\left(1-v^{2}\right)} R^{1-n / 2} B^{n} h^{3+n / 2}
$$

Given an experimental $\log -\log$ plot of $P$ vs. $h$, we extracted values of $B$ and $n$ via curve-fits to eqn. 3 , and used these to build stress-strain behavior of indented lungs. Note that if $n=0$, eqn. 3 reduces to eqn. 2. This behavior was used as input in numerical models

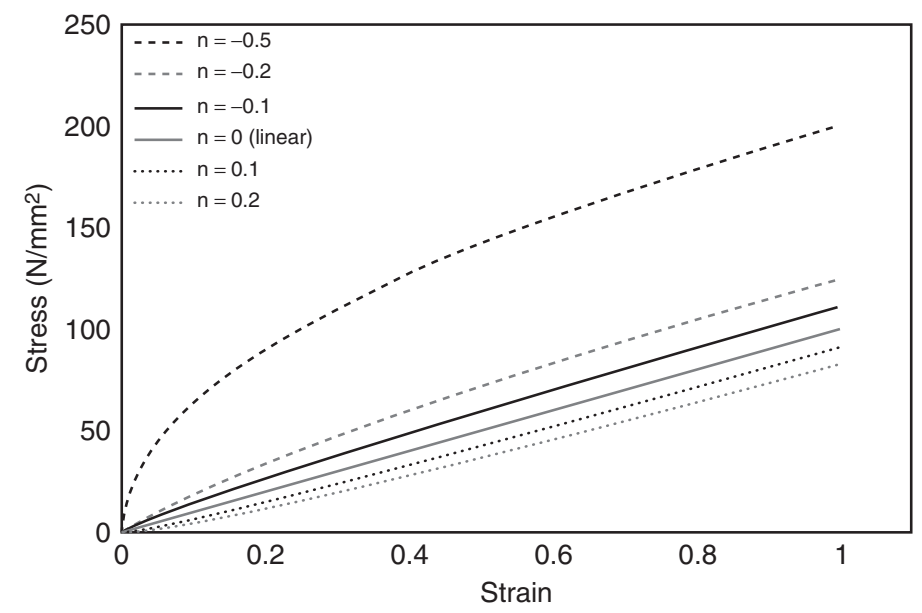

Figure 3. Modeled stress-strain behavior $\left(E_{\mathrm{o}}=200, B=1\right)$ for the Finite Element Analysis (FEA). The curves follow the relation $\sigma=\left(E_{\mathrm{o}} / n+1\right) \varepsilon^{\mathrm{n}+1}$, where $\mathrm{n} \neq-1$. Linear elastic behavior exists when $n=0$. 


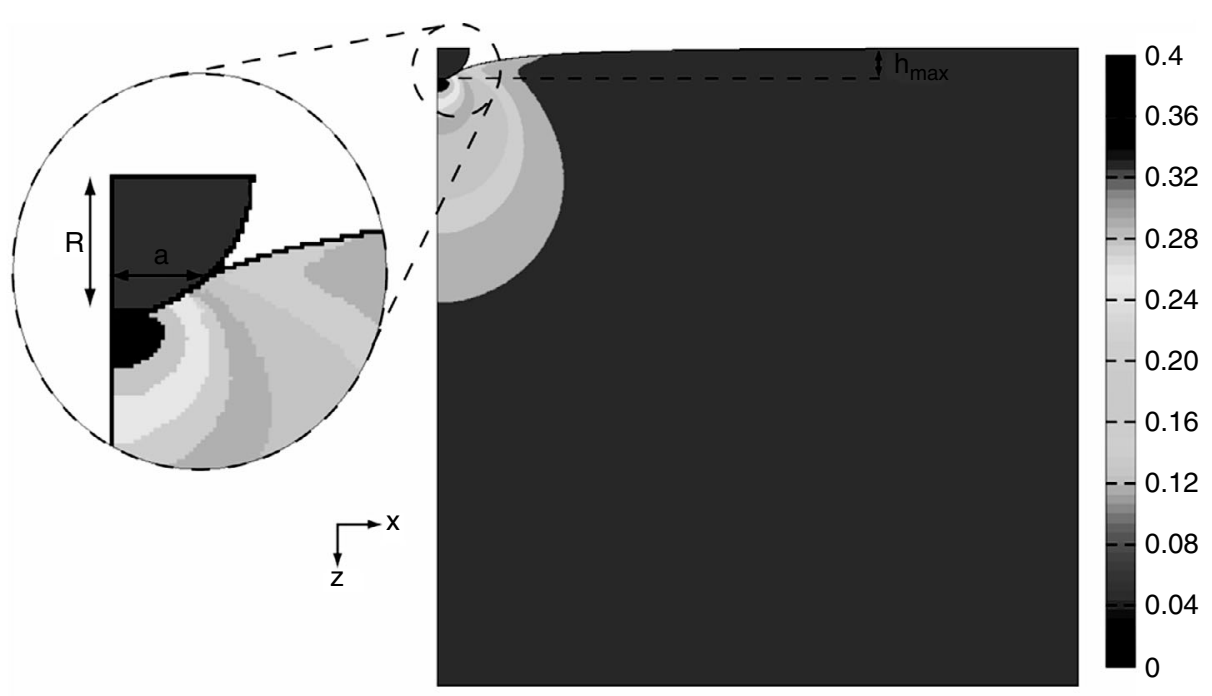

Figure 4. Image taken from FEA model, showing spherical indentation of a nonlinear elastic half-space. Model is axisymmetric about the $z$-axis (left side of domain.) Contours are compressive strain fields underneath indenter. For all later comparisons with experiments, $\varepsilon_{\mathrm{zz}}$ is extracted from points along the $z$-axis, with $z=0$ at the point of contact between indenter and surface.

of a spherical tip of radius $R$ indenting a half-space, using ANSYS, a commercial FEA code (Fig. 4). In the models, the half-space was indented to maximum depths of $h / R=0.6$ to mimic experimental deformation $\left(h_{\max }=3 \mathrm{~mm}\right.$ and $\left.R=5 \mathrm{~mm}\right)$, and strain along the axis of symmetry was extracted as a function of depth to compare to OCT results. Note that in this model, a tensed membrane to represent the visceral pleura was not included, as the size of contact was sufficient for such surface effects to be negligible [5-7]. A maximum depth of $3 \mathrm{~mm}$ would result in a 'contact radius' $a=(h R)^{1 / 2}=3.88 \mathrm{~mm} \mathrm{[21]}$.

\section{RESULTS AND DISCUSSION}

Figure 5 shows representative $P$ - $h$ data for the indentation experiments, and Tables 1, 2 and 3 show the ratio of the hysteresis values of the $P$ - $h$ curves comparing effects of gas and indentation depth, respectively. It should be noted that the data were loading-rateindependent; only results of $0.01 \mathrm{~mm} / \mathrm{s}$ loading speed are presented. For all the loading curves, $P$ has a non-linear dependence on $h$. This is expected for a spherical tip, as described in Methods. $P$ - $h$ hysteresis increases with indentation depths for both gases. However, dependence on inflation pressure is different for air and $\mathrm{O}_{2}$, as hysteresis increases with inflation pressure in air, but the reverse is true for $\mathrm{O}_{2}$ when hysteresis at $25 \mathrm{cmH}_{2} \mathrm{O}$ is compared to that at 4 and $12 \mathrm{cmH}_{2} \mathrm{O}$. Also, at the lower inflation pressures, hysteresis with $\mathrm{O}_{2}$ is about twice that under air. In all cases, the lungs inflated 
(a)

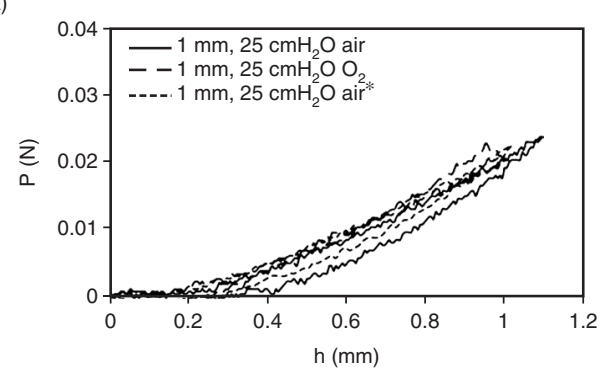

(b)

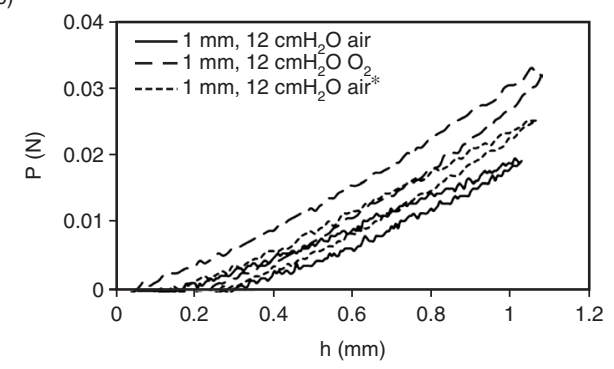

(c)

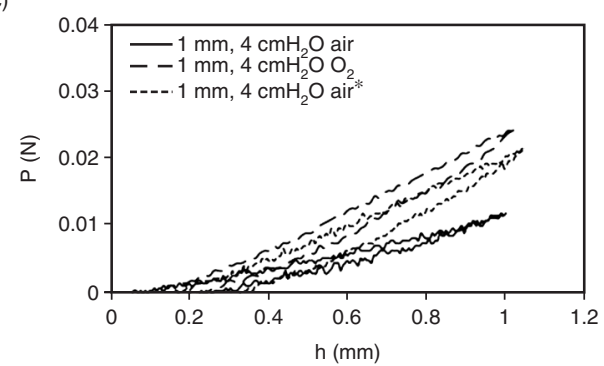

(d)

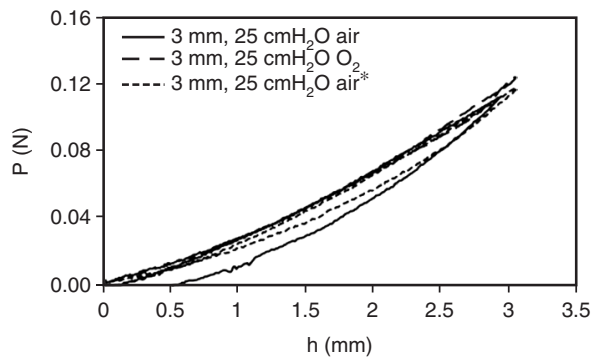

(e)

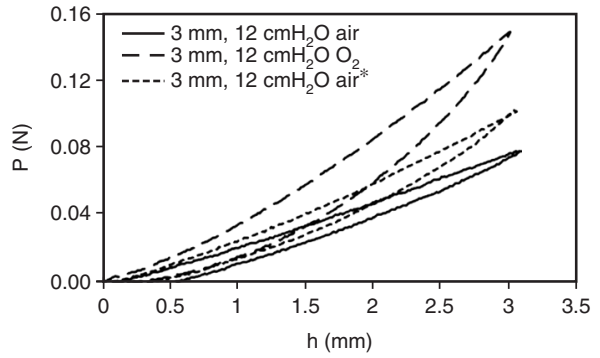

(f)

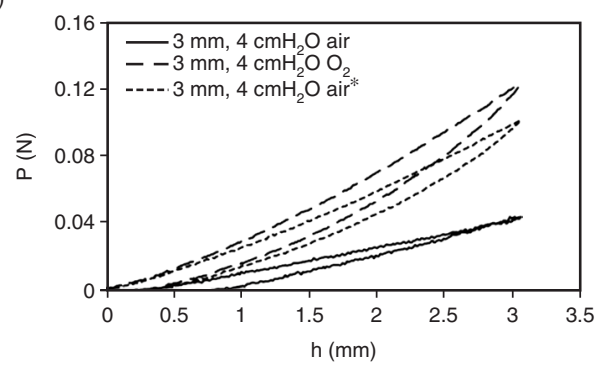

Figure 5. Representative $P$ - $h$ data for the indentation experiments. Air $=$ Lung filled with air before exposure to $\mathrm{O}_{2} ; \mathrm{O}_{2}=$ Lung filled with $\mathrm{O}_{2}$; Air* $=$ Lung filled with air after exposure to $\mathrm{O}_{2}$.

with $100 \% \mathrm{O}_{2}$ (referred to as " $\mathrm{O}_{2}$ lungs") are significantly stiffer than those inflated with air (referred to as "Air lungs"). The difference between $\mathrm{O}_{2}$ and Air lungs is most apparent at the lowest inflation pressures for all experiments. At the highest inflation pressures, there is almost no difference between the $\mathrm{O}_{2}$ and Air lungs. After re-inflation with air (five tidal volumes), reversibility of $P-h$ behavior seems to be dependent on inflation pressure, as shown by data at $12 \mathrm{cmH}_{2} \mathrm{O}$ that stiffness returns to about halfway between that for $\mathrm{O}_{2}$ and Air, whereas at $4 \mathrm{cmH}_{2} \mathrm{O}$, it only recovers by about $25 \%$. All of the experimental data for $P_{\max }$ vs. $h_{\max }$ are displayed in Fig. 6. 
Table 1. Ratio of $\mathrm{O}_{2} /$ Air hysteresis for different inflation pressures and indentation depths

\begin{tabular}{ccc}
\hline $\begin{array}{c}\mathbf{h}_{\text {max }} \\
(\mathbf{m m})\end{array}$ & $\begin{array}{c}\text { Inflation Pressure } \\
\left(\mathbf{c m H}_{\mathbf{2}} \boldsymbol{O}\right)\end{array}$ & $\begin{array}{c}\text { Hysteresis Ratio (Gas) } \\
\mathbf{O}_{2}: \text { Air }\end{array}$ \\
\hline \multirow{3}{*}{1} & 4 & 2.106 \\
& 12 & 2.479 \\
& 25 & 0.267 \\
3 & 4 & 2.299 \\
& 12 & 2.102 \\
& 25 & -0.086
\end{tabular}

Table 2. Ratio of $3 \mathrm{~mm} h_{\max } / 1 \mathrm{~mm} h_{\max }$ hysteresis for different inflation pressures, for Air and $\mathrm{O}_{2}$

\begin{tabular}{ccc}
\hline $\begin{array}{c}\text { Inflation Pressure } \\
\left(\mathbf{c m H}_{\mathbf{2}} \boldsymbol{O}\right)\end{array}$ & Air & $\begin{array}{c}\text { Hysteresis Ratio }\left(\mathbf{h}_{\text {max }}\right) \\
\text { 3mm:1mm }\end{array}$ \\
\hline 4 & 14.771 & $\mathbf{O}_{\mathbf{2}}$ \\
\hline 12 & 13.999 & 16.127 \\
25 & 15.176 & 11.898 \\
& & -4.867
\end{tabular}

Table 3. Ratio of hysteresis at 25 or $12 \mathrm{cmH}_{2} \mathrm{O}$ to hysteresis at 12 or $4 \mathrm{cmH}_{2} \mathrm{O}$, for air and $\mathrm{O}_{2}$ at $1 \mathrm{~mm}$ and $3 \mathrm{~mm}$ indentation depths

\begin{tabular}{|c|c|c|c|c|}
\hline \multirow{2}{*}{$\begin{array}{c}\frac{\mathrm{h}_{\max }(\mathrm{mm})}{\text { Hysteresis Ratio (Pressure) }} \\
\left(\mathrm{cmH}_{2} \mathrm{O}: \mathrm{cmH}_{2} \mathrm{O}\right)\end{array}$} & \multicolumn{2}{|c|}{1} & \multicolumn{2}{|c|}{3} \\
\hline & Air & $\mathbf{O}_{2}$ & Air & $\mathbf{O}_{2}$ \\
\hline $25: 4$ & 2.287 & 0.290 & 2.350 & -0.088 \\
\hline $25: 12$ & 1.390 & 0.150 & 1.506 & -0.061 \\
\hline $12: 4$ & 1.646 & 1.933 & 1.560 & 1.426 \\
\hline
\end{tabular}

Figure 7 shows the loading portion of different experimental $P$ - $h$ curves along with curve fits to determine $B$ and $n$ for this set of data. Recall that for a linear elastic material, $P$ is proportional to $h^{3 / 2}$. For all of the present experimental data, the power index of $h$ is lower than 3/2, suggesting a nonlinear behavior (see 2.6. Analysis and FEA Modeling). Further, in all cases, inflation with $\mathrm{O}_{2}$ not only increases the stiffness under 
(a)

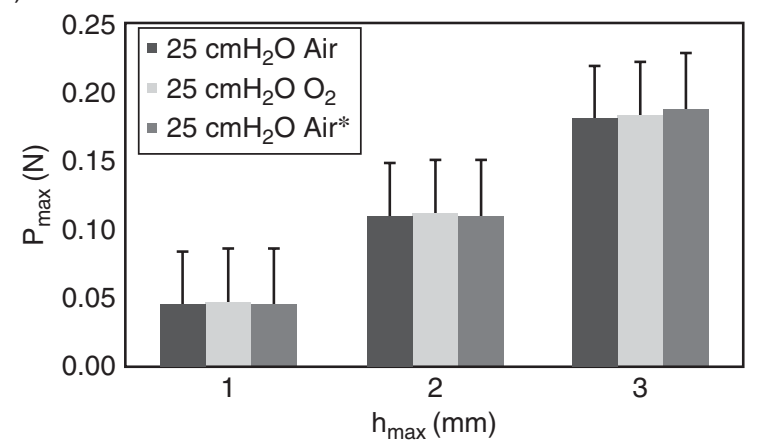

(b)

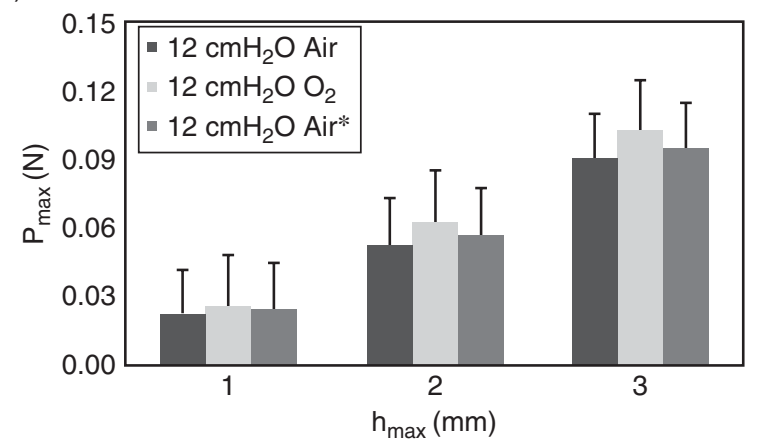

(c)

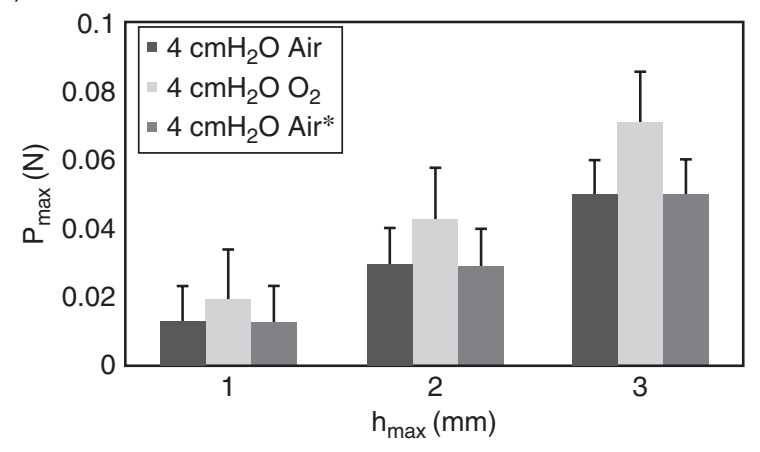

Figure 6. Bar graphs of $P_{\max }$ representing averaged values for all experimental indentation parameters along with standard errors. Air $=$ Lung filled with air before exposure to $\mathrm{O}_{2} ; \mathrm{O}_{2}=$ Lung filled with $\mathrm{O}_{2} ;$ Air* ${ }^{*}$ Lung filled with air after exposure to $\mathrm{O}_{2}$. 


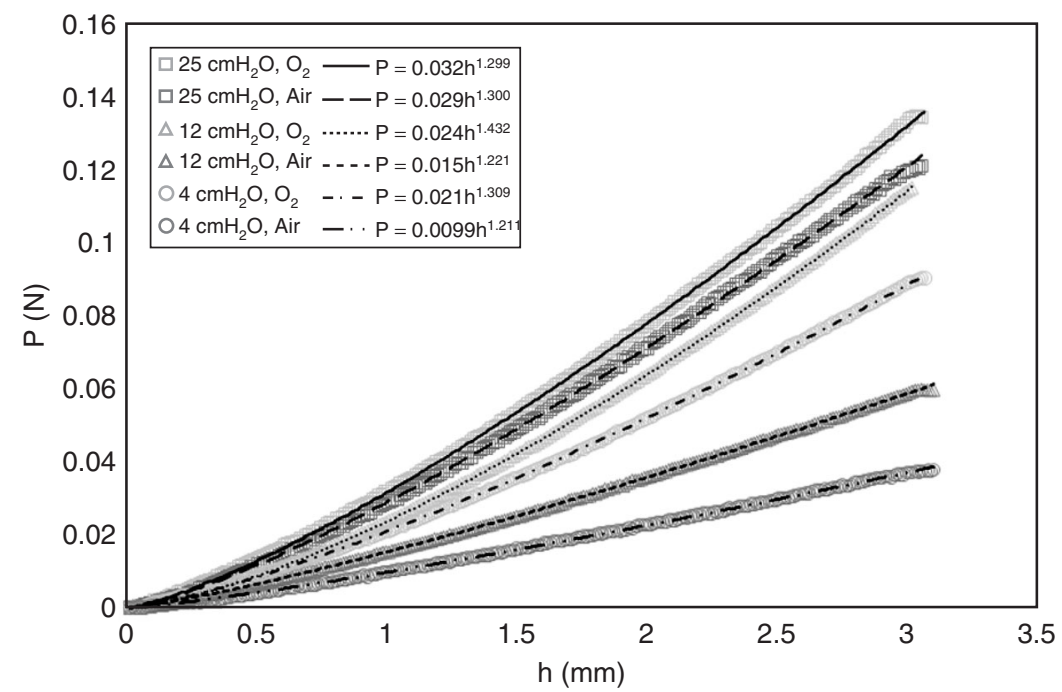

Figure 7. Experimental loading curves along with curve fits using equation (3) to determine $B$ and $n$. Air = Lung filled with air before exposure to $\mathrm{O}_{2}$; $\mathrm{O}_{2}=$ Lung filled with $\mathrm{O}_{2}$.

Table 4. Values of $\boldsymbol{n}$ obtained from curve-fitting of indentation loading data

\begin{tabular}{ccc}
\hline Inflation Pressure $\left(\mathrm{cmH}_{\mathbf{2}} \mathbf{O}\right)$ & Air & $\mathbf{O}_{\mathbf{2}}$ \\
\hline 4 & -0.578 & -0.382 \\
12 & -0.558 & -0.136 \\
25 & -0.400 & -0.402
\end{tabular}

indentation, but also raises the dependence of $P$ on $h$ (i.e., increases the value of $n$ in eqn. 3). This implies that $\mathrm{O}_{2}$ has a stronger effect at higher strains. The representative data are consistent with the overall observations, as Table 4 presents averaged values of $n$ for all the experiments, showing the same trend with $\mathrm{O}_{2}$. In all cases, $n<0$, indicating a decrease in stiffness with strain.

OCT images taken during the indentation experiments are exhibited in Fig. 8 with the region for closure analysis shown in the upper-left pane. For the most part, the closure we observed was reversible with very little permanent deformation observed. Therefore, 'closure' is a visualization of compressive strain distribution. Quantitative data of closure, calculated using eqn. 1, are displayed in Fig. 9. It is observed that alveolar closure increases with indentation depth for 12 and $25 \mathrm{cmH}_{2} \mathrm{O}$ inflation pressure, but the increase from $h=2 \mathrm{~mm}$ to $3 \mathrm{~mm}$ is not significant for $4 \mathrm{~cm} \mathrm{H}_{2} \mathrm{O}$. Figure 10 displays alveolar closure as a function of depth beneath the indenter tip. The plots indicate that for the most part, alveolar collapse is more localized in the case of 


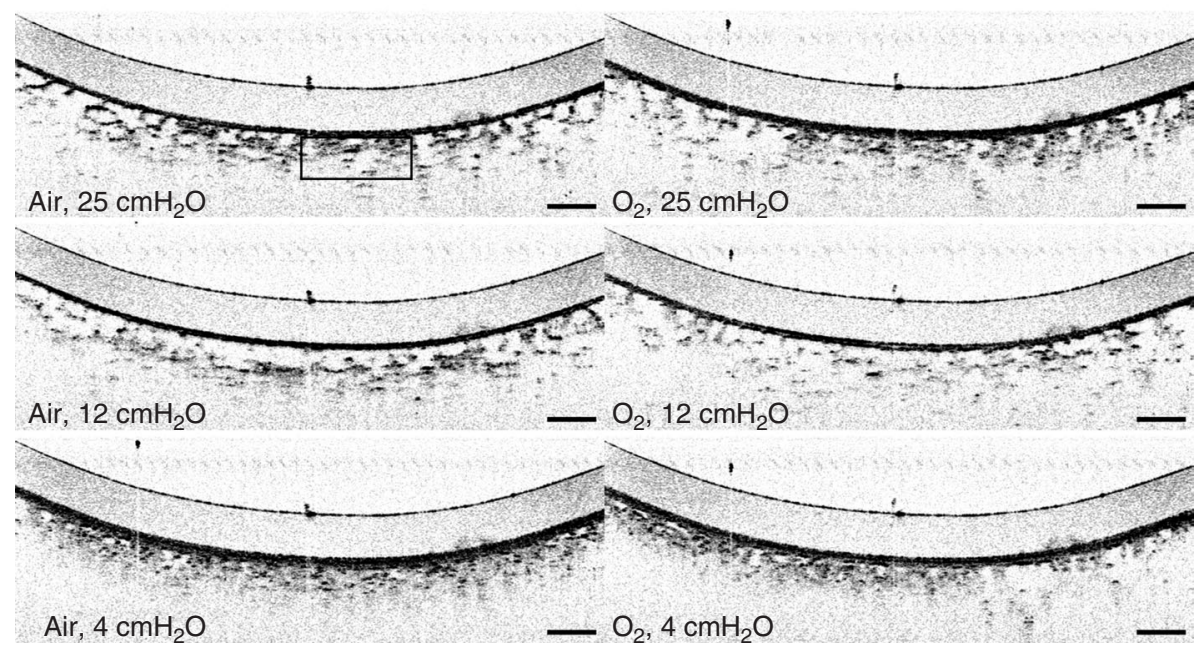

Figure 8. OCT images showing alveolar closure under $3 \mathrm{~mm}$ indentation. Gas and inflation pressure are indicated in each image. Box in the upper-left image shows region from which closure was calculated. Images are actual size (not skewed) and scale bar is $0.3 \mathrm{~mm}$.

the Air lungs, and more spread out in the $\mathrm{O}_{2}$ lungs. As with the other experiments, this effect is more significant at low inflation pressures and higher indentation depths.

The indentation and OCT experimental results can be correlated by considering the nonlinear mechanical behavior of the lung. We already approximated the mechanical stress-strain behavior of the lung in compression by considering the $P$ - $h$ dependence (Table 1). We also show here that the increased value of $n$ for the $\mathrm{O}_{2}$ lung behavior is consistent with sub-surface observations of alveolar closure, by modeling compressive strain distributions for different values of $n$. Figure 11 shows the compressive strain $\left(\varepsilon_{\mathrm{zz}}\right)$ along the loading axis for different values of $n$, with constant $a / R$ and indentation depth of $3 \mathrm{~mm}$. For $n=0, \varepsilon_{\text {zz }}$ can be calculated by the following eqn. [21]:

$$
\varepsilon_{z z}=\frac{1}{\pi R} \frac{2 a}{\left(1-v^{2}\right)}\left[\left(-1+\frac{z^{2}}{a^{2}}\right)^{-1}-2 v\left(-(1+v)\left(1-\frac{z}{a} \tan ^{-1}\left(\frac{a}{z}\right)\right)+\frac{1}{2}\left(-1+\frac{z^{2}}{a^{2}}\right)^{-1}\right)\right]
$$

The above equation indicates that $\varepsilon_{\mathrm{zz}}$ is independent of $E$. The value $v=0.43$ for lung was used for the present calculation [6]. For other values of $n, \varepsilon_{\mathrm{zz}}$ was numerically determined by the FEA model. Figure 11 demonstrates that as $n$ increases, the influence of compression due to indentation reaches deeper into the tissue (greater $\varepsilon_{\mathrm{zz}}$ at large $z$ ). As shown in Fig. 7 and Table 4, Air lungs have a lower value of $n$ than $\mathrm{O}_{2}$ lungs, and the distribution of closure (Fig. 10) is consistent with the FEA results. 
(a)

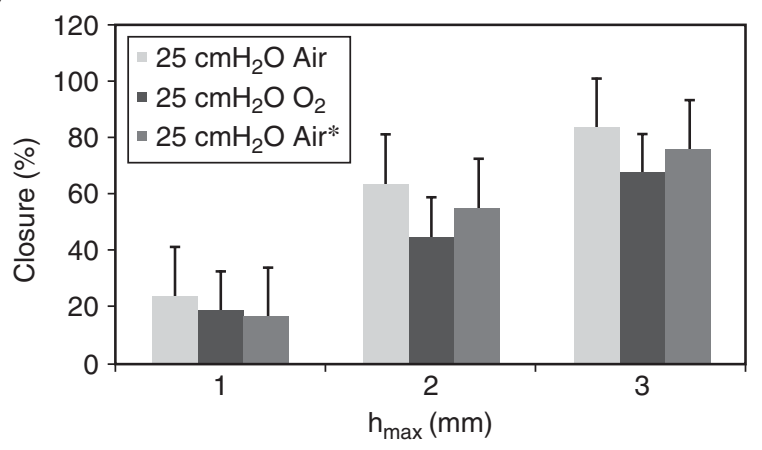

(b)

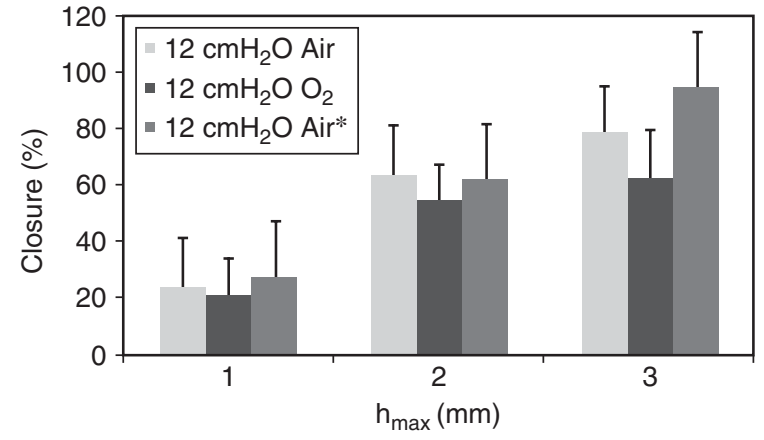

(c)

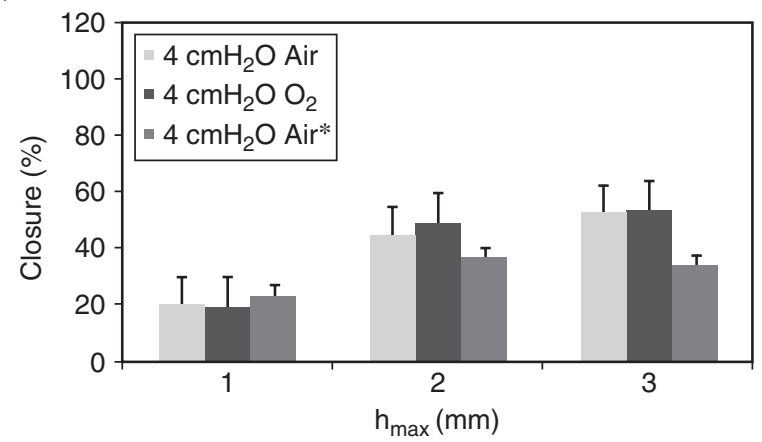

Figure 9. Averaged closure for all experiments calculated using eqn. 1.

In summary, the results of the indentation experiments and FEA modeling demonstrate the following:

- Under indentation, lungs inflated with $100 \% \mathrm{O}_{2}$ show an immediate and significant increase in stiffness, and some reversibility with a subsequent five tidal volumes of air.

- The effect of $100 \% \mathrm{O}_{2}$ is greater at a lower inflation pressure.

- Compressive deformation, manifested as alveolar closure, reaches deeper into the tissue under inflation with $100 \% \mathrm{O}_{2}$. This is consistent with a higher value of $n$ observed in the indentation experiments. 
Journal of Healthcare Engineering ' Vol. 1 · No. 3 · 2010

427

(a)

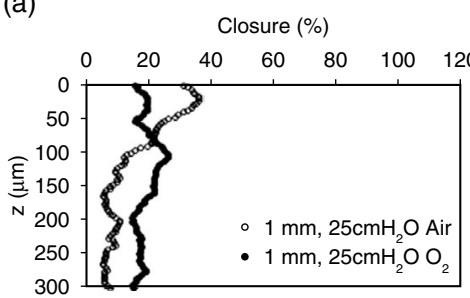

(c)

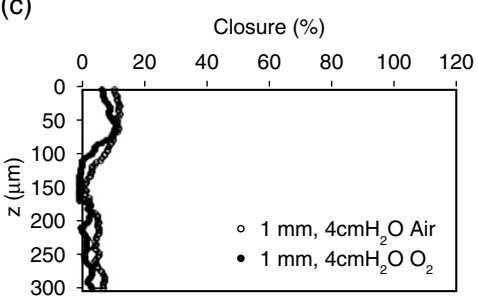

(e)

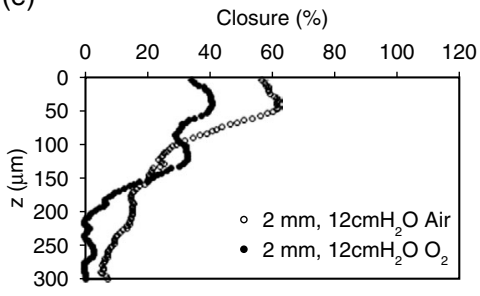

(g)

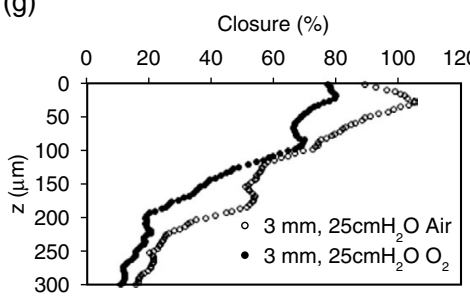

(b)

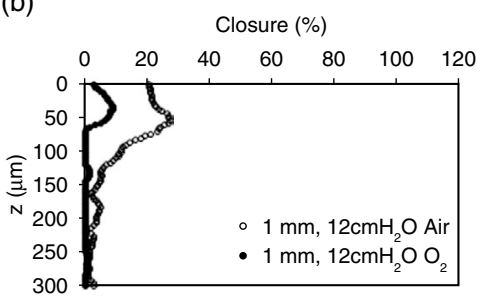

(d)

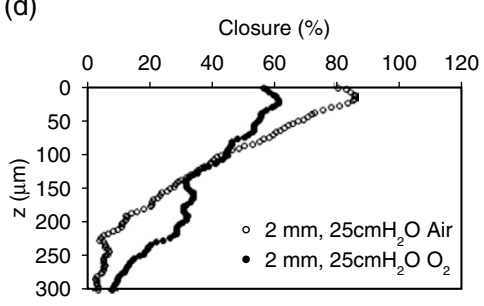

(f)

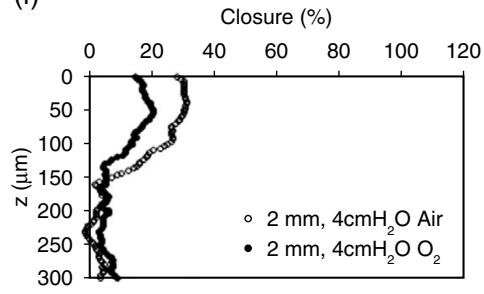

(h)

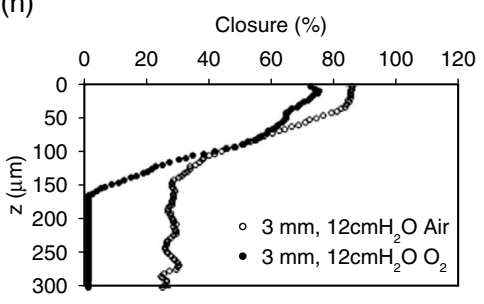

(i)

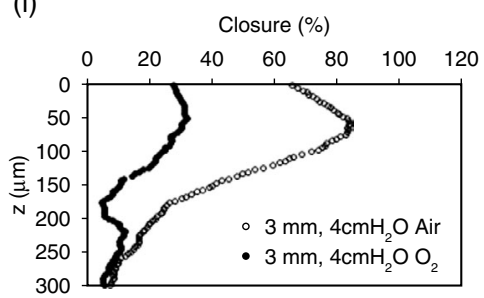

Figure 10. Closure as a function of depth, showing distribution. Left axis on all images shows vertical distance under indenter tip, and closure was calculated according to eqn. 1. Key: Air = Lungs filled with air, before exposure to $\mathrm{O}_{2} ; \mathrm{O}_{2}=$ Lungs filled with $\mathrm{O}_{2}$. 


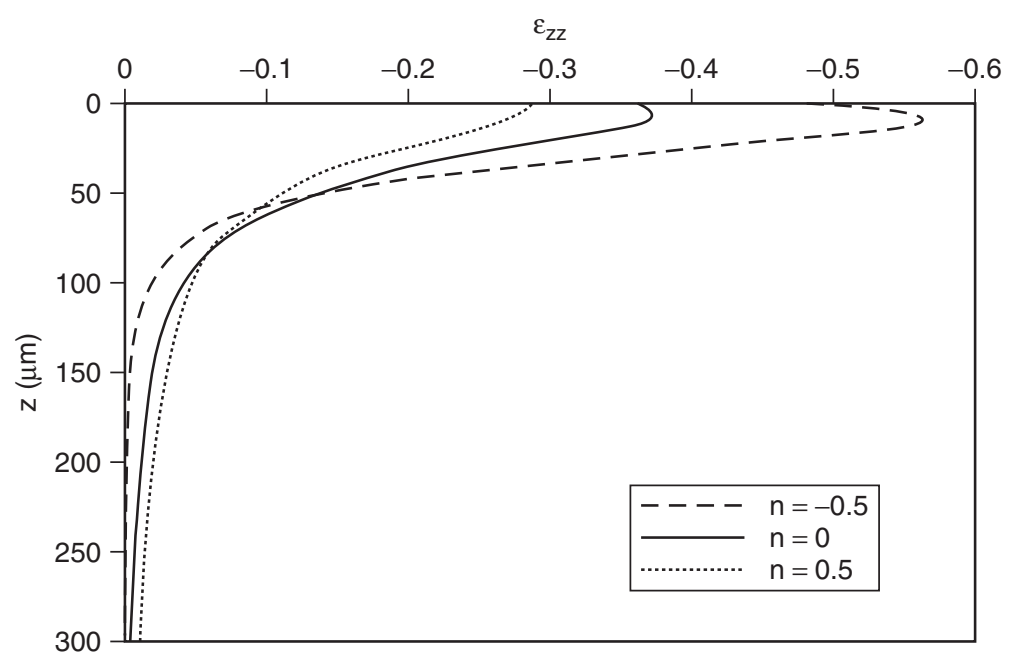

Figure 11. Results of compressive strain $\varepsilon_{z z}$ along the loading $z$-axis under a spherical indenter for different values of $n$. For $n=0, \varepsilon_{\mathrm{zz}}$ is calculated using eqn. 4 , with $R=5 \mathrm{~mm}$ and $a=3.88 \mathrm{~mm}$. For other values of $n, \varepsilon_{\mathrm{zz}}$ is determined by FEA numerical results.

\section{PHYSIOLOGIC DISCUSSION}

It is known in the respiratory literature that breathing high concentration $\mathrm{O}_{2}$ causes insult to the lung [22] (hyperoxia, oxygen toxicity). This is in agreement with the present experiments in that pulmonary behavior is dependent upon inhaled $\mathrm{O}_{2}$ concentration. However, most deleterious effects are often assessed via symptoms after hours of exposure [22,23], or post-mortem histology [22]. This does not specifically agree with the short times ( $\sim 1$ minute) we observed for significant mechanical impact to occur. In addition, cellular inflammation and damage is usually described as a primary toxic mechanism $[22,24,25]$ in hyperoxia. Cellular damage may have occurred in our experiments, but we suggest that if such damage were solely responsible for the alteration in mechanical behavior, we would have observed the greatest effect at highest inflation pressures where tissue properties contribute more to pulmonary mechanics.

Surfactant dysfunction has also been hypothesized to play a role in oxygen toxicity. Although we did not measure surfactant properties directly, here we provide a discussion of aspects in which our observations agree or disagree with this theory. It is known that the mechanical behavior of alveolar structures is dominated at lower pressures by the complex surfactant layer on their walls [8-14]. Surfactant is a mixture of surfactant proteins and phospholipids of which dipalmitoylphosphatidylcholine (DPPC) is the most surface active component once it adsorbs or respreads onto the airliquid interface with the assistance of the surfactant proteins SP-A, B, and C [12]. The surfactant is produced by alveolar type II cells, with a turnover time between 3 and 11 hours [13]. 
The primary function of the surfactant is to reduce surface tension on the alveolar walls, thus increasing compliance of the lung parenchyma to dilation and shear [4]. During a spherical indentation test, alveoli undergo a combination of uniaxial compression and shear (see Fig. 8). It appears that when alveoli are 'squashed', the walls that are nominally parallel to indentation direction are subjected to an increased curvature, requiring increased recruitment of surfactant to that region to maintain compliance. Any disruption of this function would cause an increase in indentation stiffness, as we observe in the $P$ - $h$ experiments during inflation with $\mathrm{O}_{2}$. In addition, as tissue mechanics plays a more important role at higher inflation pressures, we observed a less significant effect of reduced surfactant function at the highest pressure in our experiments.

The present experiments and models also showed an increased effect of $\mathrm{O}_{2}$ on stiffness at greater indentation depths $(3 \mathrm{~mm}$ vs. $1 \mathrm{~mm})$. This is an important result suggesting that lung stiffness not only increases with $\mathrm{O}_{2}$, but also has a greater dependence on distortion (strain). This also agrees with the observation of greater (less negative) $n$ during $\mathrm{O}_{2}$ inflation (Table 1). The present OCT observations show that distortion manifested by alveolar closure reaches deeper underneath the indenter during $\mathrm{O}_{2}$ inflation. This suggests that the increased stiffness with larger distortion at the alveolar walls causes accommodation of the indenter with a more evenly distributed, lower strain. If surfactant plays a predominant role under these conditions, it is possible that under $\mathrm{O}_{2}$ inflation, (i) surfactant function decreases at higher strains, or (ii) surfactant recruitment is hindered.

Isolated dog surfactant properties have been measured under pure atmospheric $\mathrm{O}_{2}$ by Wildeboer-Venema $[26,27]$ who found a decrease in maximum and minimum surface tension relative to air, but also observed that this effect was temporary and non-specific to $\mathrm{O}_{2}$. This was attributed to stagnation of gas in the surfactant monolayer [27]. Although Wildeboer-Venema submitted the compression ratio in the balance experiments was too high $(80 \%)$ to be physiologic, a decrease in surface tension under $\mathrm{O}_{2}$ does not explain our experimental findings. However, it has long been postulated that the structure and function of surfactant are affected by breathing rate, as DPPC molecules do not only float on the surface of an aqueous sub-phase, but are desorbed from and adsorbed to the gasliquid interface upon high compression and unloading. Krueger, et al. have provided quantitative relations between pulsating bubble surfactometer (PBS) data (pressure-volume) and diffusion constants of surfactant under different conditions [28]. It is known that surfactant proteins have a large role to play in surfactant transport to and from the fluid surface $[10,12]$. It is also generally agreed that proteins affect fluidity of surface DPPC molecules, and are directly related to transport of surfactant to and from the type II epithelial cells where it is produced $[10,12]$. Rodriguez-Capote, et al. showed that oxidative species, including Fenton reagents (e.g., $\mathrm{H}_{2} \mathrm{O}_{2}$ ) dissolved in the aqueous subphase, deactivated SP-B in extracted bovine lung surfactant [29]. In the context of our work, this would hinder surfactant transport, and increase stiffness at higher strains as we observed. In another study by Gilliard, et al., lavaged porcine surfactant was exposed to oxidating conditions $\left(\mathrm{CuCl}_{2}\right.$, or $\mathrm{FeCl}_{2}+\mathrm{H}_{2} \mathrm{O}_{2}$ in the aqueous subphase), and a loss of surface tension lowering function was observed [30]. Neither investigation studied the effects of increased $\mathrm{O}_{2}$ in the surrounding gas phase on SP-B or surfactant function, nor 
did they examine reversibility. A possible connection may be found in a study on oxygen toxicity by the Crapo group [24] who reported that increased $\mathrm{O}_{2}$ concentration in the atmosphere immediately increases the mitochondrial $\mathrm{H}_{2} \mathrm{O}_{2}$ production. It is possible that this could impair surfactant function and explain the present indentation results, but this hypothesis needs to be tested. Further, $\mathrm{H}_{2} \mathrm{O}_{2}$ production has been discussed as a culprit for cell damage [22, 24, 25]. This time scale (minutes) matches the effects seen in our experiments, and this type of cellular effect could affect tissue mechanics. However, in tests on rats exposed to air and $100 \% \mathrm{O}_{2}$ for 60-66 hours, Beckman and Weiss showed that rat lung compliance (measured using $P-V$ ) was decreased after long exposure to $\mathrm{O}_{2}$, similar to the effect of surfactant washout [23]. They also concluded that surfactant dysfunction has the dominant effect on compliance change, but noted that even large changes in tissue stiffness could have less noticeable effects on overall pulmonary mechanics. Thus, even if cellular or tissue effects occur quickly, they may not have such a significant response as observed in the current investigation. In another paper, exogenous surfactant therapy was successfully attempted to reduce the apparent toxicity of oxygen in rabbit lungs [31].. We found no work on immediate or short term effect of pure oxygen on pulmonary mechanics of intact lung. Future work would be (i) to perform $P-V$ tests on perfused lungs exposed to oxygen (and air), and to investigate effects on mechanics over time, and (ii) to expose isolated, lavaged surfactant and epithelial cell sublayer system to oxygen atmosphere in order to address our speculations.

Other physiologic arguments could contribute to the observations in this work. Dewar, et al. showed that after breathing $100 \% \mathrm{O}_{2}$ for 5 hours, human subjects displayed up to $30 \%$ increased airway resistance [32]. Such an effect could perhaps explain increased stiffness under indentation, but it is not known if resistance increases significantly in the short-term commensurate with the time span of our experiments. Another argument could be an increased propensity of $100 \% \mathrm{O}_{2}$ to diffuse across the alveolar membrane causing atelectasis. This could explain the increased hysteresis in our mechanical tests at lower pressures with $\mathrm{O}_{2}$, but perhaps does not agree with the observations that (i) most alveolar closure was reversible, and (ii) overall, closure under air and $\mathrm{O}_{2}$ had similar magnitudes (Fig. 9), and only distribution was affected by the different gases. Relative humidity (RH) has a significant effect on pulmonary surfactant properties in that $100 \% \mathrm{RH}$ increases minimum surface tension [33]. As stated above, we did not measure this value in our experiments, but if $\mathrm{O}_{2}$ is significantly more humid than air, it could produce trends in mechanical behavior similar to our observations.

\section{CONCLUSION AND CLINICAL REMARKS}

Our results of indentation tests on excised lung specimens showed that within five tidal volumes of breathing $100 \%$ oxygen, lung mechanics are significantly altered. At lower lung inflation pressure $\left(P=4,12 \mathrm{cmH}_{2} \mathrm{O}\right)$, lungs show increased stiffness, hysteresis, nonlinear stiffness (increased stiffness with strains) and hysteresis. After a subsequent five tidal volumes of air, mechanical behavior of the lung began to return to pre- $\mathrm{O}_{2}$ levels, with up to $25 \%$ recovery. In-situ subsurface observations of alveolar closure under indentation showed more localized deformation under air than $100 \% \mathrm{O}_{2}$, and this was in agreement 
with the increased nonlinear stiffness observed. The effects of $100 \% \mathrm{O}_{2}$ were almost negligible for lungs inflated to higher pressures $\left(P=25 \mathrm{cmH}_{2} \mathrm{O}\right)$. The present results provide a better understanding of the mechanism of pulmonary damage under oxygen.

\section{ACKNOWLEDGEMENTS}

This work was supported by NSF Faculty Early Career Award CMS 0449268.

\section{NOMENCLATURE}

\section{Image Analysis Parameters}

$\Sigma A_{n} \quad$ Sum of the pixel values in the chosen area of the nth OCT image frame

$\Sigma A_{o} \quad$ Sum of the pixel values in the chosen area of the first OCT image frame prior to indentation

\section{Indentation Parameters}

a Contact radius

E Young's modulus

$E_{\varepsilon} \quad$ Strain-dependent modulus

$E_{o} \quad$ Initial modulus

$E^{*} \quad$ Effective Young's modulus

$h \quad$ Indentation depth

$n \quad$ Power index of indentation depth

$P \quad$ Indentation force

$R \quad$ Radius of spherical indenter

$z \quad$ Axial distance beneath the indenter tip prior to indentation

\section{Greek}

$\varepsilon \quad$ Characteristic strain

$\varepsilon_{z z} \quad$ Compressive strain along axis of indentation

$v \quad$ Poisson's ratio

\section{REFERENCES}

[1] Udobi, K.F., Childs, E. and Touijer, K., Acute Respiratory Distress Syndrome, Am. Fam. Physician, 2003, 67, 315-322.

[2] Sarnaik, A.P., Daphtary, K.M., Meert, K.L., Lieh-Lai, M.W., and Heidemann, S.M., Pressure-controlled Ventilation in Children with Severe Status Asthmaticus, Pediatr. Crit. Care Med., 2004, 5, 133-138.

[3] Dreyfuss, D. and Saumon, G., Ventilator-induced Lung Injury - Lessons from Experimental Studies, Am. J. Respir. Crit. Care Med., 1998, 157, 294-323.

[4] West, J.B., Respiratory Physiology - The Essentials, $6^{\text {th }}$ edn., Lippincott Williams \& Wilkins, Philadelphia, 2000.

[5] Lai-Fook, S.J., Wilson,T.A., Hyatt, R.E. and Rodarte, J.R., Elastic Constants of Inflated Lobes of Dog Lungs, J. Appl. Physiol., 1976, 40, 508-513.

[6] Hajji, M.A., Wilson, T.A., and Lai-Fook, S.J., Improved Measurements of Shear Modulus and Pleural Membrane Tension of the Lung, J. Appl. Physiol., 1979, 47, 175-181.

[7] Silva, M.R., Yuan, Z.J., Kim, J.H., Wang, Z.G., Hoyos, M., Pan, Y.T. and Gouldstone, A. Spherical Indentation of Lungs: Experiments, Modeling and Sub-surface Imaging, Journal of Materials Research, 2009, 24(3),1156-1166. 
[8] Von Neergaard, K. New Opinions About the Fundamentals of Respiratory Mechanics. The Retraction Force of the Lung in Relationship to the Surface Tension within the Alveoles [in German], Z ges exp Med., 1929, 66, 373-394.

[9] Pattle, R., Properties, Function and Origin of the Alveolar Lining Layer, Nature, 1955, 175 $1125-1126$.

[10] Clements, J.A., Surface Tension of Lung Extracts, Proc Soc Exp Biol Med., 1957, 95, 170-172.

[11] Bourbon, J.R., Pulmonary Surfactant - Biochemical, Functional, Regulatory, and Clinical Concepts, 1st ed., CRC Press, New York, 1991.

[12] Bringezu, F. Ding, J. Brezesinski, G., Waring, A.J., and Zasadzinski, J.A., Influence of Pulmonary Surfactant Protein B on Model Lung Surfactant Monolayers, Langmuir, 2002, 18, 2319-2325.

[13] Zuo, Y.Y., Veldhuizen, R.A.W., Neumann, A.W., Petersen, N.O. and Possmayer, F., Current Perspectives in Pulmonary Surfactant - Inhibition, Enhancement and Evaluation, Biochim. Biophys. Acta., 2008, 10, 1947-1977.

[14] Notter., R.H., Lung Surfactant: Basic Science and Clinical Applications, Marcel Dekker, New York; Basel, Switzerland, 2000.

[15] Popp, A., Wendel, M., Knells, L., Koch, T., and Koch, E., Imaging of the Three-Dimensional Alveolar Structure and the Alveolar Mechanics of a Ventilated and Perfused Isolated Rabbit Lung with Fourier Domain Optical Coherence Tomography, J. Biomed. Opt., 2006, 11, 014015.

[16] Hanna, N., Saltzman, D., Mukai, D., Chen, Z., Sasse, S., Milliken, J., Guo, S., Jung, W., Colt, H. and Brenner, M., Two-Dimensional and 3-Dimensional Optical Coherence Tomographic Imaging of the Airway, Lung, and Pleura, J. Thorac. Cardiovasc. Surg., 2005, 129, 615-622.

[17] Mertens, M., Tabuchi, A., Meissner, S., Krueger, A., Kertzscher, U., Pries, A. R., Affeld, K., Slutsky, A. S. , Koch, E., Kuebler, W. M., Alveolar Dynamics in Acute Lung Injury: Heterogeneous Distension Rather than Cyclic Recruitment. Critical Care Medicine, 2009, 37(9), 2604-11.

[18] Meissner, S., Knels, L., Krüger, A., Koch, T., Koch, E., Simultaneous 3D Optical Coherence Tomography and Intravital Microscopy for Imaging Subpleural Pulmonary Alveoli in Isolated Rabbit Lungs. J of Biomed Opt, 2009, 14(5), 054020.

[19] Huang, D., Swanson, E.A., Lin, C.P., Schuman, J.S., Stinson, W.G., Chang, W., Hee, M.R., Flotte, T., Gregory, K., Puliafito, C.A. and Fujimoto, J.G., Optical Coherence Tomography, Science, 1991, 254, 1178-1181.

[20] Hertz, H., Uber die Deruhrung Fester Elasticher Korper (On the Contact of Elastic Solids). J. Reine Ang. Math., 1882, 92, 156-171.

[21] Johnson, K., Contact Mechanics, Cambridge University Press, New York, 1985.

[22] Moldeus P., Bannenberg G. and Ryrfeldt A., Oxidative Stress in the Lung and Effect on Pulmonary Function, in: Chandan K. Sen, Lester Packer, Osmo Hanninen, ed., Exercise and Oxygen Toxicity, Eds:, Elsevier Science Publishers, Amsterdam, 1994, 343-357.

[23] Beckman, D.L. and Weiss, H.S., Hyperoxia Compared to Surfactant Washout on Pulmonary Compliance in Rats. J. Appl. Physiol, 1969, 26(6), 700-709.

[24] J.F. Turrens, B.A. Freeman and J.D. Crapo, Hyperoxia Increases $\mathrm{H}_{2} \mathrm{O}_{2}$ Release by Lung Mitochondria and Microsomes. Archives of Biochemistry and Biophysics, 1982, 217 (2),411-421.

[25] Repine, J.E., Scientific Perspectives on Adult Respiratory Distress Syndrome, Lancet, 1992, 339, $466-472$.

[26] Wildeboer-Venema, F.N. The Influence of Oxygen upon the Isolated Surfactant Film, Bull. Eur. Physiopathol. Respir., 1978b, 14, 131-133.

[27] Wildeboer-Venema, F.N. Influence of Nitrogen, Oxygen, Air and Alveolar Gas upon Surface Tension of Lung Surfactant, Respir Physiol. 1984, 58(1),1-14.

[28] Krueger, M.A., and Gaver, D. P. III, A Theoretical Model of Pulmonary Surfactant Multilayer Collapse under Oscillating Area Conditions, Journal of Colloid and Interface Science, 2000, 229(2), 353-364. 
[29] Rodriguez-Capote, K., Manzanarea, K.D., Haines, T. and Possmayer, F. Reactive Oxygen Species Inactivation of Surfactant Involves Structural and Functional Alterations to Surfactant Proteins SP-B and SP-C, Biophysical Journal, 2006, 90, 2808-2821.

[30] Gilliard, N. Heidt, G.P., Loredo, J,, Redl. H, Maerritt, T.A. and Spragg, R.G., Exposure of the Hydrophobic Components of Porcine Lung Surfactant to Oxidant Stress Alters Surface Tension Properties, The Journal of Clinical Investigation, 1994, 93, 2608-2615.

[31] Dewar, K.M.S., Smith, G., Spence, A.A. and Ledingham I. McA., Effect of Hyperoxia on Airways Resistance in Man, J. Appl. Physiol., 1972, 32, 486-490.

[32] Wildeboer-Venema, F. The Influences of Temperature and Humidity upon the Isolated Surfactant Film of the Dog, Respir. Physiol., 1980, 39: 63-71.

[33] Baker, R.R., Holm, B.A., Panus, P.C. and Matalon, S., Development of $\mathrm{O}_{2}$ Tolerance in Rabbits with No Increase in Antioxidant Enzymes, J. of Appl. Physiol., 1989, 66(4),1679-1684. 


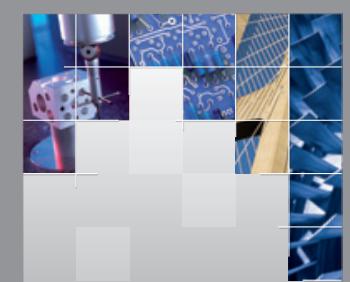

\section{Enfincering}
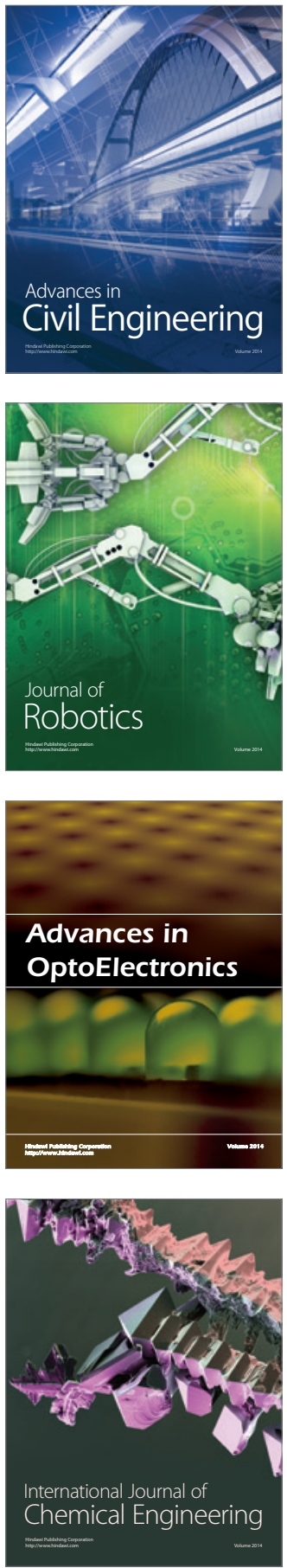

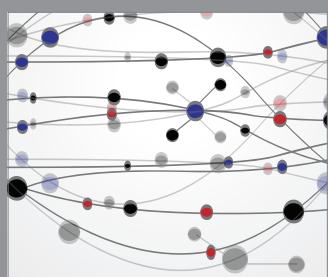

The Scientific World Journal

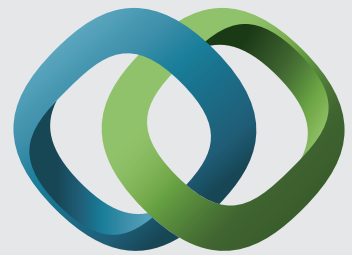

\section{Hindawi}

Submit your manuscripts at

http://www.hindawi.com
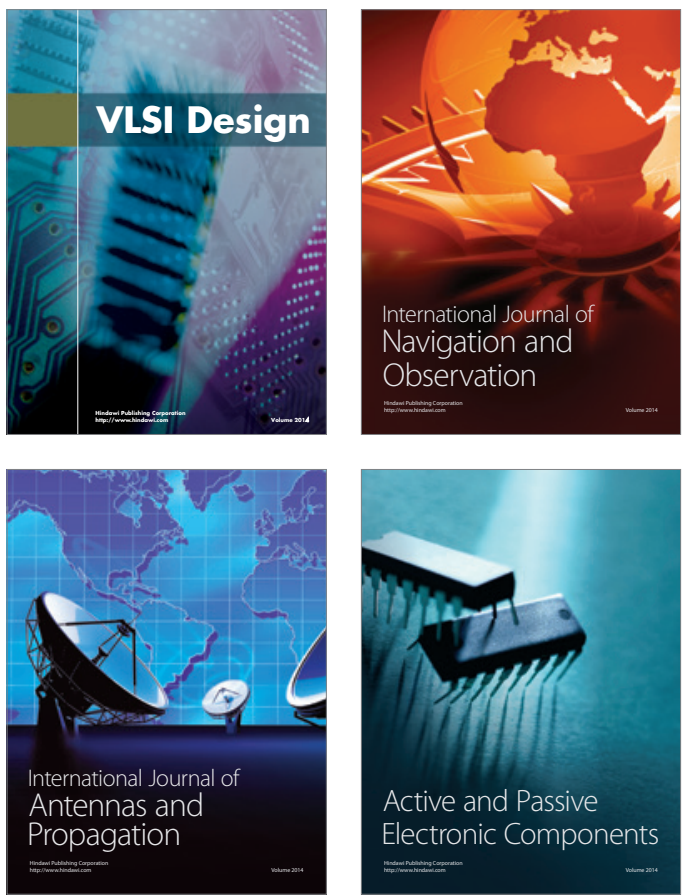
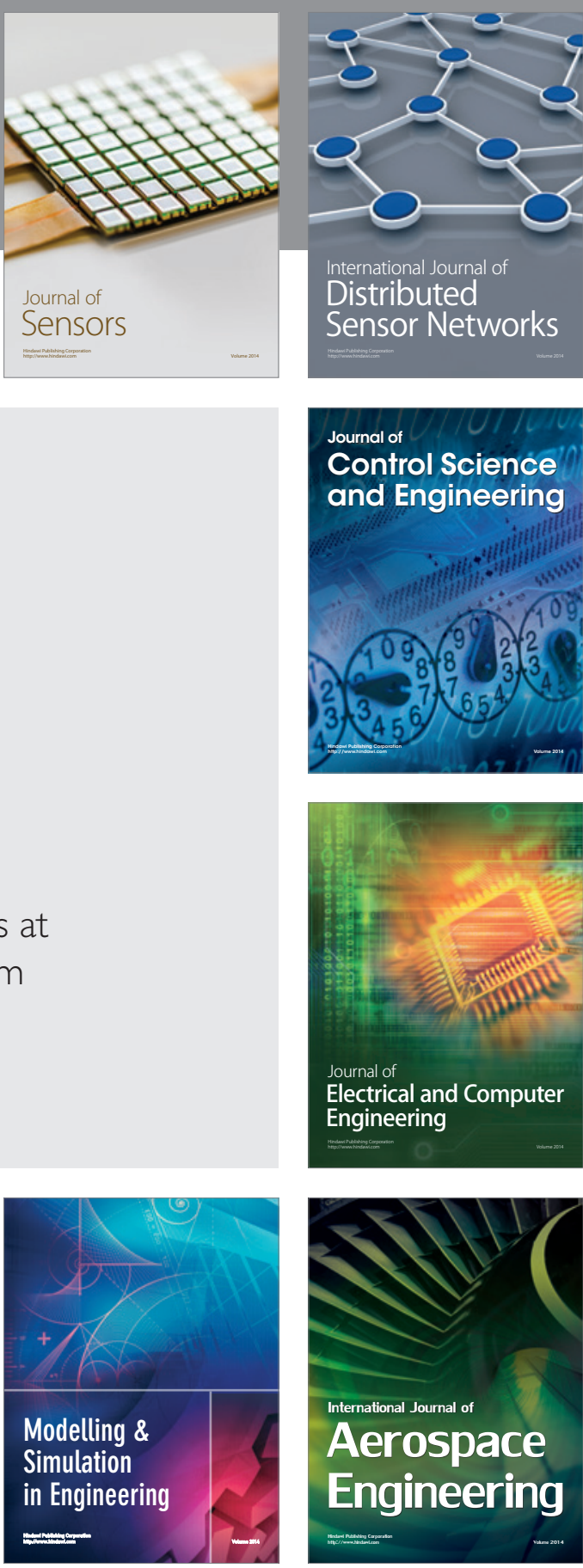

International Journal of

Distributed

Sensor Networks

Journal of

Control Science

and Engineering
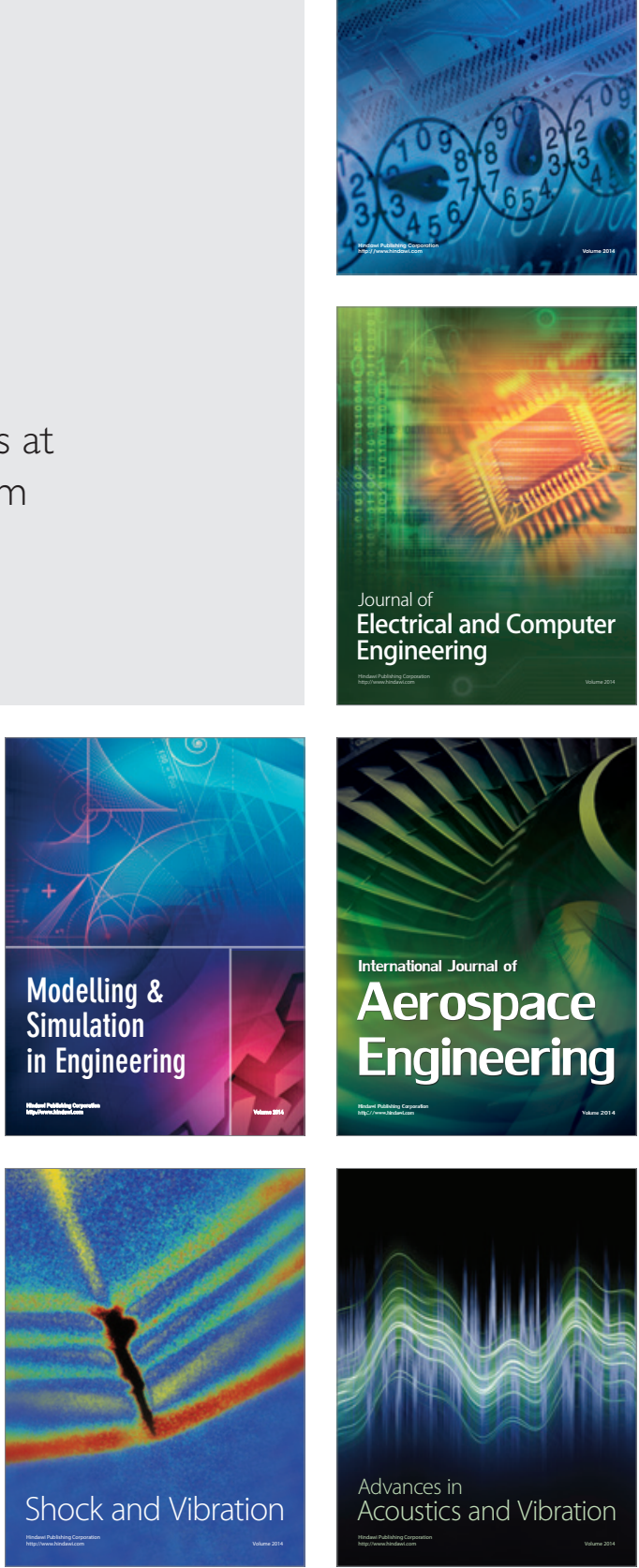